\title{
Recruitment and Selection Practices in Nigerian Institutions of Higher Learning
}

\author{
Hillary O. Odor (Corresponding author) \\ Department of Business Administration \\ Delta State Polytechnic, Ogwashi Uku \\ Delta State Nigeria
}

Tel: 234-7064334370, E-mail: odor928@gmail.com

Josephine N. Martins-Emesom

Department of Business Administration

Delta State Polytechnic, Ogwashi Uku

Delta State Nigeria

Casmir O. Bakwuye

Department of Business Administration

Delta State Polytechnic, Ogwashi Uku

Delta State Nigeria

\begin{abstract}
Recruitment and selection have become essential tools in organizations because individuals with appropriate qualifications need to be attracted in sufficient numbers and on a timely basis. The objective of this paper therefore, is to examine the recruitment and selection process and procedures in Nigeria with special reference to institutions of higher learning. This is an opinion paper which made use of secondary data and on point assessment of information from the critical sector. The study revealed that the recruitment and selection process in Nigerian higher institutions is clouded in subjectivity and not based on objective criteria that make the whole activity both inefficient and ineffective. The authors therefore, recommend that there should be a reversal of this trend first, by making the application process less complex and cumbersome so that highly qualified candidates will be motivated to apply for vacant positions. Secondly, there should be some form of objective criteria in the selection process instead of basing everything on subjectivity. Thirdly, recruitment and selection should be based on manpower needs assessment and requirement. Finally, there should be transparency in the entire process of recruitment and selection rather than behind the scene recruitment and selection. When all these are done, there will be a robust recruitment and selection process that will ensure finding the right people that will not be difficult to lead and manage in a way that maximizes the level of their individual engagement.
\end{abstract}

Keywords: recruitment, selection, employment consultants, recruitment policies, employee engagement

DOI: $10.7176 / \mathrm{EJBM} / 11-30-15$

Publication date:October $31^{\text {st }} 2019$

\section{Introduction}

It is totally uneconomical for a job applicant to send 30 copies of an application letter, 30 copies of West African School Certificate, 30 copies of first degree certificate, 30 copies of masters' degree certificate, 30 copies of PhD certificate, if gotten, and most often than not, 30 copies of birth certificate to a job advertiser by post. The post could be through speed post or through the normal snail speed post. The former is more expensive, but it gets to the destination faster than the normal snail speed post. Also, it is safer than the latter. The most agonizing is that most of these application letters do not get to the desired destination. And even when it gets there, the sorting process might be very cumbersome. It therefore, becomes a waste of resources on the part of the applicants and a waste of time on the part of the advertiser. So much work has been done in the area of recruitment and selection in the private sector, but only a few have been done in the public sector, especially in the Nigerian institution of 
higher learning.

\subsection{Statement of the Problem}

Searching for, and obtaining potential job candidates in sufficient numbers and quality and at the right cost is the best way for an organization to get the most appropriate people to fill its job vacant positions (Onyeaghala, \& Hyacinth, 2016). In recent times, there have been series of complaints about the recruitment process in the Nigerian government parastatal, especially the tertiary education sector. It has been noted that Nigerian institutions of higher learning often place advertisement for vacant positions on the print media and subsequently require interested candidates to apply manually by sending between 15 and 30 of the hard copies of their application letters, curriculum vitae, certificates and other "relevant" credentials to the advertiser through the post office. The cost on the applicant is enormous and most cumbersome. Furthermore, the fact that the applicants are not even sure of the reliability and objectivity of the process makes the whole thing more disturbing and frustrating. This process is not in tandem with modern recruitment processes and procedures of advanced technology countries. The process and the demands on the part of the candidates are quite slow and complicated. Researchers agree that the more applications received by a recruiting organization, the better the recruiter's chances of finding individuals best suited to perform the required job in the organization (Ofoegbu, 1985; McOliver, 2005). That is why most qualified candidates are not attracted to apply. When a large number of people are not attracted, there is a high probability that the best might not be selected. It is assumed that in this age of advanced technology, the recruitment process should be done using the modern day technology. It is the aforementioned problem that motivated the researchers to critically examine the process of recruitment in Nigeria tertiary institutions with a view to proffering suggestions on how to improve the process to ensure a robust hiring process.

\subsection{Objective of the Study}

The main objective of this study is to evaluate the recruitment practice in Nigerian tertiary institutions and establish a standard recruitment procedure on the basis of which the Nigerian institutions of higher could make objective and transparent recruitment and selection decisions in order to attract the best qualified candidates who have the required skills, knowledge and abilities to match available job openings in the educational system. This is because an efficient and effective recruitment and selection process enhances organizational performance. The performance in this case, is an efficient academic process which is capable of turning out sound Polytechnic and University graduates that can compete effectively with their peers anywhere in the world. Furthermore, an efficient recruitment and selection practice minimizes recruitment costs on the part of the applicant as well as reduces the rate of employee turnover. More so, making a wrong hiring decision hinders an organization from achieving its set goals and objectives.

This paper will make some recommendations on how to make a robust recruitment and selection process with a view to harnessing both the tacit and explicit knowledge of qualified candidates, who hitherto, are not always encouraged to apply for vacant positions, either because of the complicated process involved or the cost involved or because they are not sure of the objectivity of the process. When recruitment and selection exercise do not follow the principles of systemic manpower planning, scientific principles, objectivity and merit, they end up producing unqualified and incompetent graduates who can grind the educational system to a standstill.

\section{Conceptual Analysis}

Recruitment: The concept of recruitment has been variously defined by several scholars and organizational managers alike. Recruitment has become a thing of concern to many organizations and management scholars because it is only through a robust recruitment process and procedures that an organization can get a rightful candidate that can effectively fill a vacant position in the organization which according to Adeyemi and Fadere (2005) can help to put the organization in an advantageous position over its competitors. Recruitment is defined as the set of activities used to obtain a sufficient number of the right people at the rights time from the right places (Nickels, McHugh, \& McHugh, 1999). Croft (1996, p.93) defines recruitment as "the analysis of a job and the features an organization will look for in a potential employee, and attracting candidates to apply to the organization and the offering of various terms and conditions of employment to a chosen potential employee". Fatiregun (as cited in Onah 2003) opines that recruitment is the process of assessing a job, announcing the vacancy, arousing and stimulating people to apply. Walker, Feild, Giles, Armenakis, and Bernerth (2009) defined recruitment as the process of attracting a large pool of qualified people for employment. In the opinion of Omale (2006) recruitment is that process that begins with getting an applicant motivated to write an application for a particular job in a particular organization and the process stops when his application has been received by the organization. According to Monday and Noe (2005) recruitment is a process of attracting employable candidates on a timely basis, in sufficient numbers and with appropriate qualifications, developing their interest and desire in the 
organization and encouraging them to apply for jobs within it. The main purpose of recruitment, according to Cole (2002), is to attract sufficient and suitable potential employees for vacancies in the organization. Recruitment and selection are concerned with filling and keeping filled, positions in the organization structure (Koontz, \& Weihrich, 2005). From the above definitions by different scholars, a good recruitment process must be one that encourages and motivates a large pool of qualified candidates to apply for a vacant position in an organization. It is however unfortunate that the complexity involved in the application process in Nigeria is responsible for many qualified applicants not applying for several advertised vacancies.

Selection: Selection is more or less concerned with making informed decision using systematic process, to choose outstanding candidates from the available pool of prospective candidates after they have been carefully examined using appropriate selecting tools. Through selection, the performance for the job is predicted and applicants must fulfill this performance requirement before they would be selected (Yaseen, 2015). In line with the above, Ejumode (2011) argued that while recruitment brings many people or persuades as many as possible to apply for vacant positions in an organization, selection, rejects a good proportion of those who apply. He stressed that selection is a very important process that requires proper planning and objectivity and comprises the series of activities carried out to choose the most qualified applicants from the pool of prospective job candidates. To Watson (2004) recruitment and selection constitute the process of soliciting, contacting and interpreting potential employees and then establishing whether it will be appropriate or suitable to appoint them. Selection is also the process whereby human resource management uses techniques to choose qualified and capable employees from a large pool of applicants (Bratton \& Gold, 2007). The bottom line of any recruitment and selection exercise is to build and maintain a formidable workforce through which an organization can successfully satisfy its human resources plan as well as achieve its set objectives.

Bedeian (1999) maintained that where there are several job applicants for an existing position or job opening, managers or recruiting authority in both public and private sector organization must decide who is the most qualified. Such decisions are made during selection exercise. It has been observed that decision to select the most qualified staff to fill important job openings is often times based on both objective and subjective views of the interviewer. The selection stage is a very critical one considering the impact of selecting an unqualified candidate who does not have the requisite skills, knowledge and abilities to adopt to organizational tenets and culture. Casteller as cited in Otoo, Assuming and Agyei (2018) opine that the goals of a good selection process are: 1. To gather relevant information about the applicants. 2. To analyze, organize, and evaluate information of applicants to make a good choice; 3 . To assess and evaluate each applicant in order to determine their suitability to the job, and 4. To provide information of the company to applicants for them to make an informed decision whether to work for the company or not.

In the words of Onwe, Abah and Nwokwu, (2015), such candidates are only interested in collecting their monthly salaries without any commitment to the goals and objectives of the organization. Employees like those are cost centers to the organization because an organization can only be as good as the people who work in it.

The process of recruitment and selection begins with the manpower planning, which indicates areas in the organization where there are likely to be shortages of people, and the number of people to be recruited to meet anticipated employment needs (Ezeani, 2006). This is hardly ever done in Nigeria. This can be substantiated when one visit any public institution of higher learning in Nigeria and sees more than eight non teaching staff doing the job of two staff. In Nigeria for instance, recruitment is based on ethnicity, religious background, regionalism and other form of subjective criteria or tendencies. In recent years, there is hardly any academic or non academic staff that is employed in any public Nigerian university or polytechnic just on the basis of merit. It is almost impossible to be employed without a "connection" from either a politician or a very well known figure in the society. This is particularly so in the public higher institutions where advertisement for vacant positions are not made most times, sometimes even when there are made, there are just made for formality sake. It is indeed on the basis of the above that the highly qualified candidates are therefore not given the opportunity to showcase their talent and secure a job and possibly transfer part of the tacit and explicit knowledge into the students. Such candidates are left to rot with their talents, with the attendant consequences of breeding half backed graduates from our institutions of higher learning. A casual survey of some higher institutions in Nigeria by the researchers, reveal that most employed academic and non academic staff in recent time, were either not interviewed at all or they were interviewed just for formality sake. Some claimed that they have even resumed before they completed their employment application forms and other formalities. This is completely at variance with Onwe, Abah, and Nwokwu, (2015) who posit that recruitment and selection exercise has been long recognized as the most important human resources functions designed to attract and subsequently choose the best applicants to be appointed and placed on job openings in organization. That also is not aligned with Ekwoaba, Ugochukwu and Ndubuisi (2015) who argued 
that recruitments and selections have become essential in organizations because qualified candidates need to be attracted, in sufficient numbers and on a timely basis to ensure that only the best candidates are chosen for best maximum performance. Recruitment is the key to a strong and progressive academia and it is the cornerstone of any developing economy and therefore any faulty recruitment policy inflicts permanent weakness upon any economy. Therefore, the need for a sound and scientific recruitment policy is not only justified, but recommended at this point of our development. Similar to this development is the contention in National University of Ireland (2006) that the continued growth and development of an enterprise depend on its ability to recruit and select high quality personnel at all levels irrespective of the cost of such an exercise. Djabatey (2012) also have a similar opinion when he argued that for a firm to build and sustain its competitive advantage, proper staffing remains a sine qua non. Mullins (1996) buttressed this point by saying that the essence of an effective and efficient recruitment and selection exercise is for the organization to appoint the best applicant with the right ability, temperament and willingness to align him or herself with the goals and objectives of the organization.

Organizations nowadays concentrate in acquiring appropriate human capital because the employees are the most valued and most precious assets of an organization and it is the individual performance of employees that will converge to form the overall performance of the organization. While recruiting the employees, organizations have to devise a strategy to carefully recruit the most suitable employees because they create the competitive advantage for the organizations and this help to improve its performance outcomes. Selection can never be effective without having a large pool of applicant from whom to choose from.

\section{Policies and Procedures of Recruitment}

Onyeaghala and Hyacinth (2016) advises that both public and private organizations should always consider factors such as experience, educational qualification, location, etc., with no iota of bias, discrimination or favouritism during their recruitment and selection exercise.

The most important step in the process of planning to encourage and attract a pool of talented candidates into an organization is to establish sound recruitment policies and procedures. By recruitment policy, we mean an organization's standard code of conduct in respect of sourcing and attracting prospective job applicants to seek employment opportunity in an organization. According to Glueck (1992:250) recruitment policies are the broad rules that provide framework for decision making regarding employment considerations. It is important to note that every organization has recruitment policies. In some organizations, it is written while in others it is unwritten. It addresses issues concerning equal employment opportunities, source of recruitment, the recruiting authority as well as approaches to be adopted in the recruitment exercise. For instance, recruitment policy is expected to cover the following crucial issues among others: whether job opening should be advertised internally or externally; prompt reply to all job applicants with minimal delay; provision of vital information to potential employees in good faith about the job details and conditions of services, processing all applications with utmost efficiency and courtesy; seeking candidates on the basis of their qualifications for the advertised vacancy, ensuring that invited applicants for interview are given fair and a level playing ground etc (Ejumudo, 2011). None of these is done in Nigeria especially in the public sector. For there to be objective recruitment and selection exercise, organizational recruitment policy must always be a guiding compass for the recruiting authority. This is because any deviation may likely lead to costly mistakes in the recruitment processes.

\subsection{Methods and Sources of Recruitment}

Basically, there are two sources of recruitment open to any organization. These sources are classified as either internal or external. The extent to which any of the sources of recruitment will be adopted is largely dependent on specific environment of the organization and its philosophy of operation.

Internal Source allows an organization to fill vacant positions with people/staff that are already in the employ of the organization. An organization looks inward to scout for available employee with needed qualifications, skills and abilities to fill higher job openings. To Jones, George and Hill (2000), employees recruited internally are either seeking lateral moves (job changes that entail no major changes in responsibility or authority levels) like transfer or promotions. Internal sources, according to Otoo, Assuming and Agyei (2018) include promotions, transfers, internal advertisement, recall, and hiring employees the second time. Among the benefits of internal source of recruitment is that it is less expensive, less time consuming, employees are already familiar with the system and the organization has information about their abilities, skills and actual behaviour on the job. Biobele (2007) posits that internal source helps in boosting employee morale and job satisfaction, thereby enhancing workers performance and organizational productivity.

External Source involves filling job vacancies in an organization with prospective candidates from outside the 
organization. In this case, an organization looks outside for potential applicants to fill its vacant positions. In most cases, this mode of recruitment is always adopted to fill entry level positions especially during expansion, and for positions whose specific requirements cannot be adequately satisfied by employees within the employ of the organization. It should be noted that organizational policy in most cases influences the choice of method to adopt in search of applicants, while some organizational policy encourage the filling of key positions from outside, others adopt an open door policy where both employees from within the organization and others from outside are given a level playing ground to jostle for available job openings. External sources could be through any of the following:

Advertisement: This is an expensive source of generating interest in available positions. It is important that the content of an advertisement must achieve its two most important objectives as follows: Firstly, to reach the desired target audience, and secondly, to attract the required number of suitable qualified candidates so that a good choice can be made. This means that an advertisement provides a large pool of prospective candidates with requisite qualifications, abilities and skills who are motivated to seek for employment opportunities in an organization at a lower cost. Using the AIDA principle, the following can be achieved: First to gain the attention of the right people. Secondly, to create interest in the minds of those people. Thirdly, to instil a desire in them to apply for the position. Finally, to provide them with information on how apply for the position. A good advertisement should present a precise description of the job, the true picture of the organization, requisite qualification and remunerations.

Employment agencies: These are agencies whose primary responsibility is to assist in locating available managerial talents to fill top positions in an organization. Such positions could be key posts such as Chief Executive Officers or other major positions in an organization. The job descriptions and person specifications for vacant positions are lodged with the agency which subsequently matches the requirements of the job with individuals who are currently in its register or pool. These agencies have significantly contributed towards locating and attracting skillful and competent managers to fill important managerial positions in many organizations.

Employment Consultants assists an organization in designing its personnel specification. He goes further to crosscheck his files to see if he can contact job applicants with needed qualifications, abilities, skills and experience. When suitable candidates are not readily available in the consultant's pool, he can advertise, screen and draw up a list of candidates from where the organization makes it final choice.

Executive Search Consultants undertakes a special search for suitable candidates to fill important vacant positions in an organization. Like employment consultants, they maintain personal contacts with prospective talented employees. However, executive search consultancy is very expensive compared to other means. This may not be unconnected with the fact that it makes strenuous efforts to attract finest brains even from among the competitors of its clients.

Colleges/universities and vocational schools unarguably, provide a pool of talents and knowledge from which any recruiting authority or organization can tap from. This explains why various organizations' representatives pay regular visits to campuses in search of potential job candidates to fill important vacant positions in their organizations. In this case, the best graduating students are considered for interview at the college bureau. Candidates who emerged successfully are after that invited to the company for final interview and subsequent selection as the case may be. Other means of external recruitment include informal network, work-ins by job hunters, professional unions and referrals. The merit of external source of recruitment include having access to potentially large applicant pool, ability to attract people who possess the abilities, skills, and knowledge needed by the organization to attain its objectives, avenue to bring in fresh blood who may possess up to date ideas/knowledge on the latest technology (Biobele, 2007).

\section{Theoretical Framework}

This study is based on system theory of Easton, D. (1966). A system, according to Rapoport (as cited in Ishiyama and Breuning (2010), is a set of interrelated entities connected by behaviour and history. Specifically, he stated that a system must satisfy the following criteria: One can specify a set of identifiable elements; among some of the elements, one can specify identifiable relations; certain relations imply others; a certain complex of relations at a given time implies a certain complex (or one of several possible complexes) at a later time. A system composed of interrelated and interdependent parts arranged in a manner that produces a unified whole, is critical in understanding all parts of the recruitment policy process. When we look at the institutions of higher learning as an open system, which interact with its environment through the exchange process of input to transformation to output one will understand the importance of ensuring that the recruitment process must be one that will yield the ultimate benefit. Systems theory is based on the idea that everything is part of a larger, interdependent arrangement. It centers on clarifying its different parts, aligning it with the whole and establishing the relationship between or 
among them (Bertalanffy, 1962). In a nutshell, system approach is therefore, useful for viewing the relationship between interdependent parts in terms of how these relationships affect the performance of the overall system. It provides recruitment managers with a critical perspective to view and understand how to make recruitment policy to respond to the needs of the citizens as well as that of the civil service of the federation. There is a great connectivity here because a faulty recruitment process will adversely affect the society from where the unqualified candidates were chosen. In that case, you are giving back to the society what the society has given to you. This is because a system is a set of interrelated part and when one of the parts is not functioning properly, it affects the output of the entire process.

\section{Recruitment and selection process in Nigerian Civil Service}

Onwe, Abah and Nwokwu (2015) examined the impact of politics on the process of recruitment and selection exercise in the Nigerian civil service with special attention on Ebonyi State civil service using content analysis. Their study revealed that politics is a regular feature in the Nigerian civil service recruitment exercise. Onyeaghala and Hyacinth (2016) examined the effect of selection process on employee productivity in private and public sectors. The findings of the study revealed that, there is a significant difference between the selection process employed by the private and public sector organizations and the productivity they achieved by employing such selection process. They also discovered that the factors influencing selection process in private and public sector organizations are similar. Ekwoaba, Ugochukwu, and Ndubuisi, (2015) conducted a study on the impact of recruitment and selection criteria on organizational performance. From their study, it was discovered that selection criteria have significant effect on organization's performance. It was equally found that the more credible the selection criteria are the better for an organization in terms of performance outcomes.

According to Ayoade (2000) effective recruitment practice reduces labour turnover and enhances employee morale $\mathrm{He}$ argued that basing recruitment, appointment and promotion on the Federal Character principle usually discriminate against merit and encourages the selection of mediocres who have little or nothing to contribute towards organizational goals. Igbokwe, Chinyeaka and Agbodike (2015) established that, there is a significant relationship between recruitment policies and practices and employees performance in Nigerian federal civil service. They further concluded that the Nigerian federal civil service is faced with poor recruitment policies and practices which have negatively affected service delivery.

Raymond and Caroline (2005), carried out an investigation on the factors influencing employee selection in the public service in Kenya. The study used a descriptive design and it was found that a strong positive relationship exists between employee selection and the public service. Also, employee selection mechanisms such as academic qualifications, background checks, work experience and personal characteristics affect pre-employment process. According to Gberevbie (2011) staff recruitment in the Delta State Civil Service is a mixture of merit, political consideration, and element of 'god fatherism' and equal representation of citizens. Usman and Okafor (2015) posit that emphasis on connections and informal contacts, and inadequate utilization of some significant sources of recruitment, constitute the major challenges facing the recruitment of personnel in the civil service. These challenges have created difficulties for the federal civil service to appoint the right persons for the right jobs based on the principles of merit and equal opportunities for all citizens.

Ulasi [2011] researched on "HRM and productivity in Nigerian public sector". Descriptive survey design was adopted. The major findings of the study revealed that; recruitment and selection processes affect the productivity of public sector workers. Ikwesi [2010] studied the effects of recruitment and selection procedures on the efficiency of the public service in Nigeria, descriptive survey design was applied and the major findings revealed that: recruitment and selection procedures in public service are not strictly followed; politicization and other informal processes dominate the established recruitment and selection procedures. Berry, Petrin, Gravelle and Farmer (2011) writing on Issues in special education teacher recruitment, retention, and professional development, observed that there is a conscious effort by educational agencies and institutions to recruit qualified and professional teachers since they have a direct influence on the learning outcomes of the educational process. Moreso, it is no longer news that the transition to a new government always heralds appointments of people from the same locality, relations, friends and associates of the governor into the public service. That explains why whenever there is a change of government, the dialect of the new governor assumes the lingua franca in the state government house. This shows that people from the same locality with the number one citizen are given undue consideration for appointment even when there is obvious employment embargo. According to Osakwe (2007) politics of recruitment is the recruitment and selection that are based on political patronage or one that is determined by the political class. To Omeje and Ndukwe (2009), politicization of recruitment is the unconventional practice of employing political interest by those in the public offices to fill existing and nonexisting vacancies in the public service and without following due process. This is therefore the process of 
recruitment and selection that is based on subjective factors other than merit and competence criteria. According to Onwe, Abah and Nwokwu (2015), members of the public have expressed utter displeasure on this trend and have attributed it to factors such as inadequate and invalid standards for evaluating job candidates, sources of attracting potential applicants, transparency and independence of the recruiting authority.

\section{Conclusion}

Recruitment and selection practices in Nigeria is highly subjective since there is significantly no objective measure in the assessment of candidates to be placed on employment. Recruitment and selection is more often than not based on connection either with politicians or very influential persons in the society. This is why employment vacancies in government-owned institutions are not always advertized and even when they are advertized it is only to fulfill official bureaucracies. Most other times, it is a known fact that interviews are not used as the basis of selection and when they are made, it is highly subjective. It is indeed the quality of the recruitment and selection process that has affected the quality of the Nigerian graduates, because an unqualified lecturer cannot give what he does not have. And indeed education remains the engine of any economy, it is no longer strange to hear that the quality of education in Nigeria is declining and there is a potential danger that if nothing is not done urgently, our educational system will collapse very shortly. The reasons for this are not farfetched. The most fundamental reason is that the quality of lecturers employed to teach the students are very low because the mode of the recruitment process is not based on objective criteria. This is more so especially in the public institution of higher learning, although it is also a consequence of a very poor process of recruitment and selection of teachers at the primary and secondary school levels. There is therefore the dire need for a review of our recruitment and selection process with a view to recruiting and selecting only the best out of the multitude of candidates that apply for vacant positions. In trying to achieve the above, a careful and well - planned recruitment and selection of employees is absolutely necessary, in order to ensure that only the right caliber of staff is employed in our institutions of higher learning so that our graduates can compete effectively with their counterparts anywhere in the world.

\section{Recommendations}

Recruitment and selection are core human resources management functions and should be competently handled by experts in the field of human resources management because the success and survival of an organization, depends to a large extent on the caliber of its employees.

Recruitment and selection exercise in public institutions of higher learning should be merit and action based, with the potency of generating and sustaining the requisite skilled, knowledgeable and developed human resources that will be properly grounded in their various areas of specialization. Constant interference in the issue of recruitment by political office holders and other top government functionaries should be minimized or completely stopped in order to ensure credible recruitment process that will give opportunities to talented candidates which will in the long run lead to high quality of our polytechnic and university graduates.

Recruitment should be made to conform to modern technologies whereby one can apply online, by filling an online application forms or by just sending only electronic copy of curriculum vitae, instead of sending the hard between 20 and 30 an application letter and other credentials by post. Shortlisted candidates may then be asked to submit their credentials or go to the interview with the copies their credentials.

Government should also put in place stiffer punitive measures for those commercializing government appointments so as to instill sanity and fairness in the system. Therefore, objectivity should be the rule of the game if productivity and effective service delivery is sought for, to reposition our higher educational system. A good recruitment policy should be one that incorporates best practices and equal opportunities guidelines. Applicants must not receive more or less favourable treatment on the grounds of gender, race, disability, sexual orientation, marital status, family responsibility, ethnic origin, trade union membership and political and religious beliefs.

For our graduates to compete effectively with their peers worldwide recruitment and selection policies of both academic and non academic staff should be unduly restricted to only the privilege few who either have "connections" in the schools or have political "godfathers". Concerted effort must be made to ensure that they absorb the most qualified, technically sound, disciplined and committed candidates that would in turn help in turning out graduates that can stand on their feet anywhere they go.

\section{References}

Adeyemi, O. S,. Dumade, E. O,. \& Fadare, O. M,. (2015). The influence of recruitment and selection on organizational performance the influence of recruitment and selection on organizational performance. 
International Journal of Advanced Academic Research - Social Sciences and Education, 4(3), 1-63.

Ayoade, J. A. A. (2000). The federal character principle and the search for national development. In K. Amuwo Agbaje, A., Suberu, R. and Herault, G. (eds). Federalism and Political Restructuring in Nigeria. Spectrum Books, Ibadan.

Bedeian, A. G. (1999). Management. Chicago: Dryden Press.

Berry, A. B., Petrin, R. A., Gravelle, M. L., \& Farmer, T. W. (2011). Issues in special education teacher recruitment, retention, and professional development: Considerations in supporting rural teachers. Rural Special Education Quarterly, 30(4), 3-11.

Biobele, R. B. (2007). Problems of Recruitment in Civil Service: Case of the Nigerian Civil Service. African Journal of Business Management 1(6), 142-153.

Bratton, J. \& Gold, J. (2007). Strategic human resource management. London: Palgrave Macmillan.

Cole, G. A. (2002) Personnel and Human Resource Management. London: International Padstow Cornwall.

Croft, L. (1996); Management and organization. Sheffield: Hallam University

Djabatey, E. N. (2012). Recruitment and selection practices of organisation: a case study of HFC Bank (GH) Ltd. Unpublished thesis submitted to the Institute of Distance Learning, Kwame Nkrumah University of Science and Technology. Ghana: Kwame Nkrumah University of Science and Technology.

Easton, D. (1966). A Systems Analysis of Political Life. New York: Wiley

Ejumudo, K. B. O. (2011). Constraints in the staff recruitment and selection system of Delta state civil service. Department of Political Science, Delta University, Abraka, Nigeria.

Ekwoaba, J.O, Ugochukwu, U.I, Ndubuisi, U. (2015) The impact of recruitment and selection criteria on organizational performance. Global Journal of Human Resource Management 3, 22-33.

Ezeani, O. (2006). Fundamentals of Public Administration. Enugu: Snaap Press Ltd.

Fatiregun, E. O. (1992). Recruitment, Selection and Placement Processes in A. D. Yahaya and Akinyele, C. I. (eds) New Trends in Personnel Management: A Book of Reading. Lagos: Administrative Staff College of Nigeria.

Glueck, W. F. (1992). Personnel: A Diagnostic Approach. Texas: Business Publication.

Igbokwe, I., Chinyeaka, J. \& Agbodike, F. (2015). Recruitment policies in the Nigerian federal civil service and their implications on employee performance. Kuwait Chapter of Arabian Journal of Business and Management Review, 5(3), 34-48.

Ikwesi, P.S (2010). The effects of recruitment and selection procedures on the efficiency of the public service in Nigeria. Unpublished Dissertation submitted to the University of Nigeria, Nsukka.

Irwin, R. (2003). Study guide: Staff selection and appraisal; Southern Cross University, Lismore.

Ishiyama, J. T., \& Breuning, M. (2010) Systems theory and structural functionalism. Los Angeles: Sage.

John, G. K, Raymond, M.N., \& Caroline, N. M (2014). Factors influencing employee selection in the public service in Kenya. International Journal of Economics, Commerce and Management 2, 1-15.

Jones G. R., George J. M., \& Hill C. W. L. (2000). Contemporary management, (2nd Ed). Irwin: McGrawHill.

Koontz, H. and Weihrich, H. (2005). Management: A Global Perspective. New Jersey: McGraw-Hall. M c O 1 i v e r, F. O. (2005). Management in Nigeria: Philosophy and practices. International Journal of Communication and Humanistic Studies, 2(1), 17-31. 
Mondy , R.W., \& Noe, R.M (2005) The ecology of recruitment and selection of personnel in the federal civil services of Nigeria. Journal of Human Ecology 17 (1), 31-37.

Mufu, G.F. (2015) Recruitment and selection: The case of National Oil Refinery Company-SO.NA.RA (Sarl), Cameroon. An unpublished Master thesis in strategic human resources management \& labour relations.

Nickels, W. G., McHugh J. M., \& McHugh S. M. (1999). Understanding business, (5th Ed). USA: Irwin/McGrawHill.

O f o e g b u , R. (1985). Personnel recruitment and management. In H. N. Nwosu (ed) Problems of Nigerian administration. Enugu: Fourth Dimension Publishing Co. Ltd.

Omale, I. (2006) Principles and practices of personnel management: From recruitment to retirement. Makurdi: Aboki Press.

Onah, F. O. (2003). Human resource management. Nsukka: Fulladu Publishing Co.

(Onwe, S.O., Abah, E.O., \& Nwokwu, P.M. (2015). Politics of recruitment and selection in the Nigerian civil service - An Ebonyi State experience. Public Policy and Administration Research, 5(2), 92-99.

Onyeaghala, O.H., \& Hyacinth, M.I. (2016). Effects of employee selection process on productivity in the public and private sectors: A Case of Benue State. Business and Economics Journal, 7(4), 1-8.

Onah, F. O. (2003). Human resource management. Nsukka: Fulladu Publishing Co.

Otoo, I.C., Assuming, J., \& Agyei, P.M. (2018). Effectiveness of recruitment and selection practices in public sector higher education institutions: Evidence from Ghana. European Scientific Journal, 14(13), 199-214.

Ulasi, N.A. (2011). Human resource management and productivity in Nigeria public sector. University of Nigeria Enugu Campus.

Usman and Okafor (2015). A Critical analysis of the recruitment policy of the Nigerian civil service. International Journal of Social Sciences and Humanities Reviews, 5(1), 26-33.

Walker, H. J., Feild, H. S., Giles, W. F., Armenakis, A. A., \& Bernerth, J. B. (2009). Displaying employee testimonials on recruitment web sites: Effects of communication media, employee race, and job seeker race on organizational attraction and information credibility. Journal of Applied Psychology, 94(5), 1354-1364.

Watson, J. (2004). Public personnel management. London: Freed Press. 